\title{
O NARRADOR AUTORAL, O LEITOR CRIANÇA E A METAFICÇÃO EM "A MAIOR FLOR DO MUNDO", DE JOSÉ SARAMAGO
}

\author{
Mariana Cortez (UNILA) \\ Felipe dos Santos Matias (UNILA)
}

Resumo: O presente artigo objetiva analisar duas estratégias estéticoliterárias utilizadas em A maior flor do mundo (2001), de José Saramago (1922-2010), são elas: a relação entre o narrador autoral e o leitor pretendido e o trabalho com a metaficção na literatura infantil. Ambos os conceitos serão apresentados como procedimentos significativos na formação estética do leitor literário. Esta investigação será desenvolvida por meio de análise teórico-crítica do texto saramaguiano, utilizando as reflexões de Walter Benjamin (1994) sobre o narrador, de María Cecilia Silva-Díaz (2005) acerca da metaficção em obras para crianças e Peter Hunt (2010) em relação à definição e função da literatura infantil. O intuito dessa reflexão é desvendar as artimanhas do autor português contemporâneo no diálogo com a criança, um leitor inusitado em sua produção literária, e entender como uma obra da literatura infantil pode contribuir na formação de futuros leitores literários.

Palavras-chave: Narrador autoral; Formação do leitor; Metaficção; Literatura infantil.

Abstract: We analyze two aesthetic literary strategies used in the The biggest flower in the world (2001), by José Saramago (1922-2010): the relation between the narrator/author and the intended reader and the work with metafiction in children's literature. Both concepts will be presented as significant procedures in aesthetic education of literary reader. This research will be developed through theoretical and critical analysis of Saramago's text, using the Walter Benjamin's (1994) reflections about the narrator, María Cecilia Silva-Díaz's (2005) about metafiction in books for children, and Peter Hunt's (2010) in relation to the definition and function of children's literature. The purpose of this reflection is to unveil the tricks of this contemporary Portuguese author on his dialogue with the child, an unusual reader in his literary production and understand how a work of children's literature can contribute to the formation of future readers.

Keywords: Authorial narrator; Formation of the reader; Metafiction; Children's literature. 


\section{INTRODUÇÃO}

A obra A maior flor do mundo (2001), de José Saramago (1922-2010), permite que o leitor acompanhe a história de um menino que vive suas peripécias "fora da sossegada terra onde vivem seus pais" (SARAMAGO, 2001, p.6). O personagem-menino viaja a outros espaços além daquele imposto pela realidade. No entanto, até para a imaginação, há um pequeno limite: "Em certa altura, chegou no limite das terras até onde se aventurara sozinho" (SARAMAGO, 2001, p.9). O menino pergunta-se, então: ir ou não ir além?

O menino-herói decide aventurar-se. Depois de muito caminhar depara-se com a maior flor do mundo, mas ela está murcha. Contudo, "como este menino era especial de história" (SARAMAGO, 2001, p.14), decide salvar a flor, mas enfrentará um obstáculo - terá de buscar água em outro lugar - já que ali, onde a flor está, não há o que ela necessita. Ele, com toda disposição, busca água em outro lugar para salvar a maior flor do mundo. Terminada sua missão, retorna à casa "rodeado de todo o respeito" (SARAMAGO, 2001, p.21). o conto saramaguiano narra, portanto, o desafio do menino de encontrar água e salvar a maior flor do mundo.

Esta é uma narrativa que pode ser interpretada como um conto que propõe reflexões acerca do meio ambiente, a 
qual pode ser lida como a história do esforço do menino ou mesmo de sua capacidade imaginativa. O modo de narrar, porém, é o destaque dessa obra destinada ao público infantil, pois para contar a saga do menino herói, o narrador adverte, já no começo da narração, que utilizará de recursos estéticoliterários que conduzirão a uma reflexão sobre a função da literatura infantil na construção de futuros leitores.

\section{CONSIDERAÇÕES SOBRE O NARRADOR}

Para Walter Benjamin (1994), no ensaio $O$ narrador - considerações sobre a obra de Nicolai Leskov (1936), a figura de Heródoto é o exemplo mais bem acabado do narrador, no qual se poderiam encontrar os traços perenes e paradigmáticos do contador de histórias tradicional, cuja arte de contar entrou em declínio a partir da Modernidade. Esse narrador era o responsável pela plasticização de uma história capaz de prender a atenção e suscitar o espanto e a reflexão, respaldada na experiência individual e coletiva, semelhante, de acordo com o ensaísta alemão, "às milenares sementes de trigo, encontradas nas pirâmides do Egito e que, no limiar do século $X X$, ainda guardavam latentes as suas forças germinativas" (p.204).

Em seu texto, Benjamin faz referência à célebre obra Histórias, de Heródoto, com o intuito de mostrar um 
narrador caracterizado pelo exímio domínio do processo de contação de histórias, visto que o historiador grego da Antiguidade não apresenta considerações ou explicações que se configurem como possibilidades interpretativas plenas e acabadas, permitindo aos seus ouvintes e leitores a tarefa de atualizar constantemente a estrutura narrativa através de interpretações diferentes, originais e sucessivas. Assim ilustra o texto abaixo:

O primeiro narrador grego foi Heródoto. No capítulo XIV do terceiro livro de suas Histórias encontramos um relato muito instrutivo. Seu tema é Psammenit. Quando o rei foi derrotado e reduzido ao cativeiro pelo rei persa Cambises, este resolveu humilhar seu cativo. Deu ordens para que Psammenit fosse posto na rua em que passaria o cortejo triunfal dos persas. Organizou esse cortejo de modo que o prisioneiro pudesse ver a sua filha degradada à condição de criada, indo ao poço com um jarro para buscar água. Enquanto todos os egípcios se lamentavam com esse espetáculo, Psammenit ficou silencioso e imóvel, com os olhos no chão; e, quando logo em seguida viu seu filho, caminhando no cortejo para ser executado, continuou imóvel. Mas, quando viu um dos seus servidores, um velho miserável, na fila dos cativos, golpeou a cabeça com os punhos e mostrou os sinais do mais profundo desespero.

Essa história nos ensina o que é a verdadeira narrativa. (1994, p.203-204) 
Ao analisar o excerto acima, observa-se que, para Benjamin, Heródoto é o narrador visto como o contador de histórias por excelência, ou seja, é aquele que conseguiu imprimir em seu texto uma configuração que privilegia a narração e as múltiplas possibilidades de interpretação e não a explicação ou a descrição propriamente dita. E devese ressaltar que o teórico alemão faz referência à arte de contar, utilizando Heródoto como o grande exemplo, para fazer apologia do narrador como um cronista, cujo artefato de seu labor é a elaboração de um relato, ou seja, uma narrativa dentre as várias possíveis.

A narrativa é, segundo Benjamin, uma forma artesanal de representação, pois ela mergulha o texto na vida do autor para em seguida retirá-la dele. Assim, imprime-se nela a marca pessoal do narrador, "como a mão do oleiro na argila do vaso" (BENJAMIN, 1994, p.204). A forma narrativa deve ser percebida por meio de perspectivas múltiplas. Em outras palavras, pode-se dizer que uma narração nunca deve ser pensada como fechada em sua construção, mas sempre aberta, passível de diversas interpretações que não alteram, nem esgotam sua particularidade. Dessa forma, toda leitura é uma interpretação que faz a obra reviver a partir de uma perspectiva original. 
As reflexões de Benjamin (1994) possibilitam pensar a narrativa como obra aberta, atualizada e transformada, na medida em que se torna uma solicitação do desejo de leitura de um sujeito. Nesse sentido, a narrativa se constrói como uma produção para a qual converge um conjunto de efeitos comunicativos, que permitem ao leitor ou ouvinte recompreender a forma originária imaginada pelo autor.

O narrador saramaguiano em A maior flor do mundo possui um caráter autoral, pois veicula o pensamento humanista do escritor. Desse modo, é permitido dizer que a diferenciação entre a persona literária do narrador e a persona empírica/ civil do autor não se aplica no caso dele ${ }^{11}$, pois Saramago possui em sua escrita literária um narrador representativo das suas ideias, pensamentos e convicções.

Para Saramago, o seu narrador o reproduz, expressa as suas opiniões dentro do texto. Dessa forma, a sua persona literária saramaguiana, enquanto criação autoral, carrega consigo a figura do próprio criador, divergindo da ideia de autor implícito de Wayne Booth. No artigo que publicou em 1998 na Revista Cult, intitulado "O autor como narrador", Saramago afirma que "a figura do narrador não existe, [...] o

$1{ }^{1}$ De acordo com Maria da Conceição Madruga, "José Saramago, em entrevistas várias [...] disse encontrar-se dentro de cada um dos seus romances, como ser humano e vivo, esgueirando-se por entre as condicionantes estilísticas do discurso ficcional". In: MADRUGA, Maria da Conceição (1998). A Paixão segundo José Saramago. Porto: Campo das Letras. p.131. 
autor exerce função narrativa real na obra de ficção" (p.26). Essa sua ideia é reforçada nas entrevistas que concedeu ao editor Torcato Sepúlveda, publicada no jornal lisboeta Público, e ao jornalista José Carlos de Vasconcelos, publicada na revista portuguesa Visão, conforme evidenciam os fragmentos a seguir:

Quando se fala dos meus livros, sempre se refere: "o seu narrador". Do ponto de vista técnico aceito que me separem a mim, autor, dessa entidade que está por lá que é o narrador. Também não vale a pena dizer que o narrador é uma espécie de "alter ego" meu. Eu iria talvez mais longe, e provavelmente com indignação de todos teóricos da literatura, afirmaria: "Narrador, não sei quem é". Parece-me, e sou leigo na matéria, que no meu caso particular - e creio ter encontrado uma fórmula que acho feliz para expressar isso - é como se eu estivesse a dizer ao leitor: "Vai aí o livro, mas esse livro leva uma pessoa dentro". Leva uma história, leva a história que se conta, leva a história das personagens, leva a tese, a filosofia, enfim, tudo o que se quiser encontrar lá. Mas além de tudo isso leva uma pessoa dentro, que é o autor. Não é o narrador. Eu não sei quem é o narrador, ou só o sei se o identificar com a pessoa que eu sou. O meu narrador não é o narrador realista, que está lá para contar o que aconteceu, sendo guiado pelo autor que por sua vez se mantém distante. Pelo contrário. Aquilo que procuro - embora sem saber 
muito bem que o faço, se calhar vou compreendendo que andava à procura depois de ter chegado - é uma fusão do autor, do narrador, da história que é contada, das personagens, do tempo em que eu vivo, do tempo em que se passam todas essas coisas. (SARAMAGO, 1991, p.7)

$[\ldots]$

Continuo a pensar que o narrador não existe, quem existe é o autor, que tem uma história na cabeça e a quer passar ao papel. E como isto para mim é quase uma regra de ouro, estou presente, admito que às vezes até demais, no que escrevo. Não para falar de mim, mas para dar as minhas opiniões, as minhas sentenças. Se não fosse a minha desconfiança visceral face a essa entidade chamada narrador, se nos meus livros houvesse um narrador canônico, eu de certa forma desapareceria e ele se encarregaria dessas opiniões e sentenças. Mas não há. (SARAMAGO, 2003, p.96)

Há na obra infantil $A$ maior flor do mundo e nos romances de Saramago de um modo geral a consciência da representação artística como veículo de subversão das verdades estabelecidas e dos discursos oficiais. Sua escrita é movida pelo desejo de dizer de um modo alternativo, de abrir fendas, de preencher vazios, de subverter a lógica de poder. O universo ficcional saramaguiano, infantil ou adulto, 
problematiza o que foi propagado como único caminho interpretativo, proporcionando ao leitor a percepção das diferentes versões de uma mesma história, e chamando a atenção para o papel ideológico desempenhado pelo autor do discurso. A respeito disso, o escritor português fez a seguinte afirmação:

De fingimentos de verdade e de verdade de fingimentos se fazem, pois, as histórias. Contudo, em minha opinião, e a despeito do que, no texto, se nos apresenta como uma evidência material, a história que ao leitor mais deveria interessar não é a que, liminarmente, Ihe é proposta pela narrativa. Um livro não está formado somente por personagens, conflitos, situações, lances, peripécias, surpresas, efeitos de estilo, exibições ginásticas de técnicas de narração - um livro é, acima de tudo, a expressão de uma parcela identificada da humanidade: o seu autor. [...] o autor está no livro todo, o autor é todo o livro. (1998, p.27)

O texto saramaguiano se nega a aceitar as narrativas, sejam elas literárias ou historiográficas, como realidades incontestáveis, pois percebe a parcialidade do autor do discurso. Inspirado nos preceitos da Nova História, Saramago faz, por meio de seu narrador, os seus leitores pensarem sobre as múltiplas possibilidades de representação. Com isso, observa-se que há no escritor português o desejo de fazer 
uma arte romanesca compromissada, que busca evidenciar ao público leitor a existência das diferentes formas de contar uma mesma história. Isso também acontece em $A$ maior flor do mundo:

Mas ao menos ficaram sabendo como a história seria, e poderão contá-la doutra maneira, com palavras mais simples do que as minhas, e talvez mais tarde venham a saber escrever histórias para as crianças...

Quem sabe um dia virei a ler outra vez esta história, escrita por ti que me lês, mas muito mais bonita? ... (SARAMAGO, 2001, p.25-26)

Saramago cria em A maior flor do mundo um jogo de forças entre um narrador experiente, mas com pouca habilidade para entender a linguagem de seu público, e um leitor inexperiente, mas com competência para desvendar a linguagem, de palavras difíceis, do mundo dos adultos. Entende-se, então, que haverá, em sua primeira obra para crianças, um narrador instaurado na narrativa que é o simulacro do próprio autor da obra.

A ilustração de João Caetano também reforça a ideia da instauração desse reflexo do autor, já que o desenho assemelha-se muito a imagem do próprio autor. Decorrente dessa constatação, é possível aproximar o autor-narrador de 
A maior flor do mundo ao narrador descrito e categorizado por Benjamin, já que o contador de histórias descrito pelo ensaísta alemão é justamente aquele ligado à tradição oral, que tem por objetivo relatar suas experiências vividas, seus desejos e suas angústias.

A maior flor do mundo coloca em cena um narrador com características de contador de histórias orais, aquele que olha nos olhos de seu interlocutor e propõe cumplicidade. Assim, como define Benjamin: "A experiência (narrativa) que passa de pessoa a pessoa é a fonte a que recorreram todos os narradores. E, entre as narrativas escritas, as melhores são as que menos se distinguem das histórias contadas pelos inúmeros narradores anônimos" (1994, p.198). Para um narrador constituir-se como tal, segundo Benjamin, deveria ser partícipe da comunidade e deveria cumprir o papel, via narrativa, do "conselheiro" daquele grupo de pessoas. Ainda, o teórico alemão aponta para uma tipologia de narradores que obedece ao seguinte critério: o camponêssedentário, aquele que narra a partir dos relatos ouvidos, e o comerciante-viajante, aquele que relata suas aventuras em terras distantes. Ambos os narradores têm função social, um acalenta com sua sabedoria acumulada pela observação da comunidade, e outro aconselha a partir de suas vivências 
no além-fronteiras. Com a criação da imprensa, contudo, o romance moderno deveria extinguir a narração, apregoava Benjamin.

A obra de Saramago, contudo, reafirma com veemência a importância do narrar e a prática da rede de histórias, já que o desfecho narrativo é uma proposta de reescrita oferecida aos pequenos leitores: "Quem sabe se um dia virei a ler outra vez esta história, escrita por ti que me lês, mas muito mais bonita?" (SARAMAGO, 2001, p.26).

\section{CONTRATO NARRADOR-AUTOR E LEITOR}

Assim, Saramago instaura o seu narrar em um jogo de contratos, em que os papéis a serem desempenhados já estão apresentados de antemão: de um lado um narrador experiente, mas que não atende às especificidades de seu leitor criança, pois, segundo ele, as crianças "sabem poucas palavras e não gostam de usá-las complicadas" (SARAMAGO, 2001, p.1), e de outro, o narrador-autor, que não tem propriedade para escolher as palavras adequadas e, principalmente não domina um modo de narrar "um jeito certo de contar, uma maneira muito certa e muito explicada" (SARAMAGO, 2001, p.1). Há, dessa forma, um rebaixamento das qualidades do narrador. No entanto, esta também é uma estratégia argumentativa, em que se reconhecem 
as qualidades do interlocutor para assim convencê-lo. À medida da desqualificação do autor-narrador, revelam-se as características do leitor que se pretende: um leitor criança e como tal com dificuldade para, num susto, entrar no universo literário do adulto. Esse gesto de "colocar as cartas na mesa" é "olhar nos olhos" do leitor, propondo, portanto, um jogo de "igual para igual":

As histórias para crianças devem ser escritas com palavras muito simples, porque as crianças, sendo pequenas, sabem poucas palavras e não gostam de usá-las complicadas. Quem me dera saber escrever essas histórias, mas nunca fui capaz de aprender, e tenho pena. Além de ser preciso saber escolher as palavras, faz falta um certo jeito de contar, uma maneira muito certa e muito explicada, uma paciência muito grande - e a mim falta-me pelo menos a paciência, do que peço desculpa.

Se eu tivesse aquelas qualidades todas, poderia contar, com pormenores, uma linda história que um dia inventei, mas que, assim como a vão ler, é apenas o resumo de uma história, que em duas palavras se diz... (SARAMAGO, 2001, p.1-2)

Dessa cumplicidade surge o diálogo como possibilidade de troca: falamos e escutamos e assim nos modificamos e nos constituímos como sujeitos e, como consequência, leitores mais experientes. Desse ir e vir nasce a autonomia: “Agora 
vão começar a aparecer algumas palavras difíceis, mas, quem não souber, deve ir ver no dicionário ou perguntar ao professor" (SARAMAGO, 2001, p.5).

É possível entender o conto saramaguiano neste jogo de desafios - não sei narrar para crianças e, portanto, você, leitor, terá de esforçar-se, ou seja, o narrador exige uma interlocução ativa. O leitor deve exercer ao menos quatro tarefas fundamentais: a primeira, envolver-se no enredo narrativo; a segunda, refletir sobre o próprio código; a terceira, preencher os espaços vazios e, finalmente, a quarta, recontar a narrativa lida de forma mais competente. Este autor-narrador reconhece a inexperiência, mas exige a atividade do leitor. Por esses traços, Saramago desenha seu leitor-criança: alguém que escuta/lê, busca e produz conhecimento. Um interlocutor ativo diante da literatura. Tanto assim que a história termina com um convitedesafio: "Mas ao menos ficaram sabendo como a história seria, e poderão contá-la doutra maneira, com palavras mais simples que as minhas, e talvez mais tarde venham a saber escrever histórias para crianças..." (SARAMAGO, 2001, p.25).

A proposta de interlocução colocada e explicitada no enunciado é enfaticamente tratada, já que por meio desse mecanismo, bastante arriscado como procedimento argumentativo na literatura infantil, mas interessantíssimo 
do ponto de vista ideológico e literário, intensifica-se o papel do leitor diante de uma obra que exige contribuições e interpretações. Afirma-se, recuperando as propostas teóricas que abordam um papel ativo do leitor (COMPAGNON, 1999; ISER, 1979), que o autor-narrador pode construir seu leitor e a leitura mais bem-sucedida é aquela em que autor e leitor podem negociar sentidos para entrar em acordo. A leitura é também empatia, projeção, identificação. Não é o próprio livro, mas o cenário no qual se lê, as impressões que acompanharam a leitura e, principalmente, o repertório acionado no momento da leitura que contribuem e constituem a significação. Assim, "cada leitor é, quando lê, o próprio leitor de si mesmo" (PROUST Apud COMPAGNON, 1999, p.144).

\section{CONSTRUÇÃO METAFICCIONAL}

No enlace entre a obra, seu momento histórico e as características estéticas de uma determinada formação ou corrente literária, seria pertinente ponderar, para assim abrir espaço para a explicitação do conceito de metaficção na obra infantil deSaramago, que oromance contemporâneo incorporou uma das características do romance moderno, a constante presença da metaficção na narrativa, transformando-a em um aspecto nuclear na construção estética. 
As reflexões desenvolvidas por Linda Hutcheon (1991) adotam como ponto de partida essa característica da ficção romanesca atual de tematizar continuamente o próprio processo da escrita literária, promovendo a autorreflexão narrativa. Segundo Hutcheon, "grande parte da metaficção contemporânea se preocupa quase exclusivamente com seu próprio artifício, suas próprias atividades estéticas" (HUTCHEON, 1991, p.78).

Partindo das ideias da teórica canadense, percebe-se que a metalinguagem literária constrói um mundo ficcional mais ligado à realidade empírica do sujeito leitor, pois a história vai se completando com a leitura, transformando o leitor em coautor, ao mesmo tempo em que desconstrói a expectativa primeira do sujeito em relação ao texto, já que este desafia o leitor, apresentando-lhe novas regras e exigindo dele, portanto, outra postura interpretativa.

Em A maior flor do mundo, o narrador autoral saramaguiano e sua relação com o leitor pretendido propõe este jogo metaficcional. Peter Hunt (2010) reforça a perspectiva literária apresentada por Saramago, quando afirma, "o que pode ser mais significativo do que aquilo de que trata a história talvez seja o modo como ela é construída" (p.187). É, exatamente, tal tipo de procedimento que o narrador autoral saramaguiano adota no início da obra infantil $A$ maior flor do mundo: 
As histórias para crianças devem ser escritas com palavras muito simples, porque as crianças, sendo pequenas, sabem poucas palavras e não gostam de usá-las complicadas. Quem me dera saber escrever essas histórias, mas nunca fui capaz de aprender, e tenho pena. Além de ser preciso saber escolher as palavras, faz falta um certo jeito de contar, uma maneira muito certa e muito explicada, uma paciência muito grande - e a mim falta-me pelo menos a paciência, do que peço desculpa. (SARAMAGO, 2001, p.1)

O proposto por Hutcheon (1991), em sua obra Poética do pós-modernismo, trata, especificamente, da produção cultural voltada ao público adulto. Em outra perspectiva, o que se analisa neste artigo é a literatura destinada às crianças, assim sendo, pode-se pensar que a literatura infantil seria uma expressão longe da reflexão sobre o próprio código e, portanto, com características diferentes da literatura adulta. A metaficção por ser um procedimento complexo e reflexivo deveria estar (ou estaria) à margem das obras infantis, pois antes, interessaria à literatura infantil mecanismos de linguagem, em que a imaginação fosse acionada e os efeitos miméticos fossem criados. Contudo, nos tempos modernos, ou até mesmo em tempos além deles, impõe-se outro tipo de reflexão, outra forma de estar no mundo e outras formas de interagir nele, inclusive na infância. Como consequência, 
seria também possível afirmar que uma nova concepção de infância estaria em jogo.

Vale, no entanto, a ressalva de que esta "nova" maneira de estar no mundo e interagir nele já foi antecipada pelos precursores e inovadores da literatura infantil, por exemplo, em Alice no país das maravilhas, de Lewis Carroll, representando a literatura universal em meados do século XIX, e Monteiro Lobato, a brasileira do início do século XX. Ambos alteraram o estatuto do que é ser criança e ainda do que deveria ser a literatura destinada a esse público. Tais precursores alteraram esse "efeito de ficcionalidade" para voltarem-se ao próprio código de maneira crítica e reflexiva. Carroll e Lobato criaram personagens ousadas para seus tempos e espaços. Alice e Emília questionavam, cada uma ao seu modo, o ficcional, o contar ilusório e, "brechtianamente", tomaram, de alguma maneira, as rédeas da história.

Pensa-se, portanto, que a metaficção é, de alguma maneira, constituinte da literatura infantil que propõe rupturas com relação aos contos infantis mais tradicionais, pois os livros para crianças, a partir de novas concepções de infância, passaram a questionar seus valores e seus modos de inserção social e, como consequência, passaram a questionar o código e figurativizar os problemas de 
linguagem, negando o senso comum da necessidade literária de alienação do sujeito. Assim, evidencia-se que a literatura infantil apresenta os mesmos recursos, lida com os mesmos mecanismos estético-literários oferecidos pela literatura voltada ao público adulto e, por isso, constitui-se como um agente formador do leitor literário e, por meio dela, o leitor inicial pode aos poucos familiarizar-se com as artimanhas da literatura. Peter Hunt (2010), com argumentação enfática, se manifesta:

A suposição de que a literatura infantil seja necessariamente inferior a outras literaturas - para não falar que é uma contradição conceitual - é, tanto em termos linguísticos como filosóficos, insustentável. Implica também uma improvável homogeneidade entre texto e abordagem autoral, uma perspectiva ingênua da relação entre leitor e texto e uma total falta de entendimento tanto das habilidades da criança leitora como da forma como os textos operam. (p.48)

Nesta direção, A maior flor do mundo, utiliza-se da experimentação estética, voltando-se ao próprio código para com isso exigir uma leitura ativa do leitor em formação. A mesma postura crítica e atuante do narrador saramaguiano nas obras destinadas aos adultos é pretendida no texto literário destinado ao público infantil. Retomando a proposta literária daquele autor com visão humanista que não acredita 
em verdades estabelecidas, mas que reconstrói a história (ou História) por meio de novas perspectivas, novos olhares, sua obra literária para crianças, apesar de desculpar-se, possibilita ao leitor a revisão do próprio conto e do contar.

Silva-Díaz, pesquisadora da literatura infantil, no estudo La metaficción como un juego de niños contrapõe contos tradicionais a contos transgressores e aponta como característica deste último grupo a metaficção:

Es frecuente también que estos experimentos literarios transgredan las barreras entre lo que está dentro de la historia (el argumento) y lo que está fuera (la situación comunicativa, el soporte), produciendo el desconcierto del lector. Pues, por lo general, estamos acostumbrados a leer narraciones convencionales, el personaje, el narratario o la página permanecen en su debido lugar. (2005, p.5)

\section{CONSIDERAÇÕES FINAIS}

Na obra de Saramago para o público infantil, como apresentado anteriormente, o narrador autoral travará um diálogo com seu leitor, sempre rompendo com o espaço do enunciado e voltando-se ao gênero literatura infantil ("Não se temam, porém, aqueles que fora das cidades não concebem histórias nem sequer infantis"), ao espaço narrativo dos 
contos tradicionais ("Na história que eu quis escrever, mas não escrevi, havia uma aldeia..."), às próprias estratégias literárias ("Dali para diante começava o planeta Marte, efeito literário de que ele não tem responsabilidade, mas com que a liberdade do autor acha poder hoje aconchegar a frase.") e finaliza explicitando ("E essa é a moral da história").

É o narrador autoral explicitamente dialógico que autoriza a ruptura metaficcional e faz com que $A$ maior flor do mundo possa ser inserida no grupo de obras da literatura infantil que se utilizam da experimentação estética na construção da narrativa destinada às crianças. A mesma postura crítica e atuante do narrador saramaguiano nas obras destinadas ao público adulto é percebida no texto literário destinado ao público infantil. $\mathrm{O}$ mesmo procedimento estético relacionado à metaficção é utilizado na estruturação da sua narrativa direcionada às crianças, produzindo, portanto, uma narrativa instigante, que se propõe no diálogo, que visa à desconstrução de uma verdade (mesmo que ficcional) absoluta, como nos contos tradicionais. O texto saramaguiano analisado neste artigo propicia ao leitor infantil a possibilidade de conscientização da narrativa enquanto processo em construção e do valor estético da obra literária, gerando uma leitura crítico-reflexiva em contraposição 
a uma perspectiva mais "conservadora", ou seja, aquela em que o leitor é mantido em uma postura passiva com pouca possibilidade de intervenção. Os dois procedimentos estético-literários trabalhados por esta análise, o narrador autoral e a metaficção, permitem inferir a literatura infantil como formadora do leitor literário, pois como comenta Jill Paton Walsh:

O livro infantil apresenta um problema mais difícil, tecnicamente mais interessante - o de fazer uma declaração adulta inteiramente séria, como qualquer bom romance, sendo extremamente simples e transparente (...). A necessidade de compreensão impõe uma obliquidade emocional, um procedimento indireto na abordagem, que, como a elisão e a afirmação parcial na poesia, muitas vezes é fonte de força estética. (Apud HUNT, 2010, p.77)

Assim sendo, a linguagem simples que estaria à altura do leitor criança é alcançada por meio da proposta estéticoliterária do autor português, visto que sua narrativa, como apresentado, cria uma relação horizontal entre o narradorautor e o leitor, e um vai e vem real e ficcional que gera autorreflexão em relação ao processo de escrita, uma autoconsciência de que todo discurso é uma construção ideológica e de que toda história é parcial. 


\section{REFERÊNCIAS}

BENJAMIN, Walter (1994). Magia e técnica, arte e política: ensaios sobre literatura e história da cultura. Sérgio Paulo Rouanet (Trad.). 7.ed. São Paulo: Brasiliense.

BOOTH, Wayne Clayson (1980). A retórica da ficção. Maria Teresa H. Guerreiro (Trad.) . Lisboa: Arcádia.

COMPAGNON, Antoine (1999). O Demônio da Teoria: literatura e senso comum. Cleonice Paes Barreto Mourão (Trad.). Belo Horizonte: Editora da UFMG.

HUNT, Peter (2010). Crítica, teoria e literatura infantil. Cid Knipel (Trad.). São Paulo: Cosac Naify.

HUTCHEON, Linda (1991). Poética do pós-modernismo: história, teoria, ficção. Ricardo Cruz (Trad.). Rio de Janeiro: Imago.

ISER, Wolfgang (1979). A interação do texto com o leitor. In: JAUSS, Hans Robert et al. (Org.). A literatura e o leitor: textos de Estética da Recepção. Luiz Costa Lima (Trad.). Rio de Janeiro: Paz e Terra, p.83-132.

MADRUGA, Maria da Conceição (1998). A Paixão segundo José Saramago. Porto: Campo das Letras.

ROSENFELD, Anatol (1985). Reflexões sobre o romance moderno. In: Texto e contexto. São Paulo: Editora Perspectiva, p.75-97.

SARAMAGO, José (1990). História e ficção. Jornal de Letras, Artes e Ideias (JL), Lisboa, p.400.

; SEPÚLVEDA, Torcato (1991). Deus quis este livro. In: Público, Lisboa, 02 de novembro.

(1998). O autor como narrador. Revista Cult, São Paulo, p.17.

(2001). A maior flor do mundo. llustrações de João Caetano. São Paulo: Companhia das Letras.

; VASCONCELOS, José Carlos de (2003). Entrevista de José Saramago a José Carlos de Vasconcelos. In: Revista Visão, Lisboa, 16 de janeiro. 
SILVA-DÍAZ, María Cecilia (2005). La metaficción como un juego de niños: una introducción a los álbumes metaficcionales. Caracas: Banco del Libro. VASCONCELOS, José Carlos de (2010). Conversas com Saramago: os livros, a escrita, a política, o país, a vida. Lisboa: Jornal de Letras.

Mariana Cortez é Doutora em Letras (USP). Docente em UNILA. Mestrado em Literatura Comparada e Graduação em Letras - Espanhol e Português como línguas estrangeira. CORTEZ, M.; GORDILLO, D. S. A LEITURA EM CONTEXTO DE FRONTEIRA: ACERVOS E SALAS DE LEITURA INTERCULTURAIS. In: Ivan Vale de Sousa. (Org.). Leitura na Educação Básica: perspectivas e desafios. 1.ed. Jundiaí: Paco Editorial, 2017. p.3148. / ALMEIDA, R. A.; CORTEZ, M. ME GRITARON NEGRA E A CONSTRUÇÃO DA IDENTIDADE NEGRA NO CONTEXTO PERUANO. Percursos Linguísticos (UFES), 7, p.583-598, 2017. FROMELE - Grupo de Pesquisa Fronteiras da mediação de leitura em espaços interculturais. E-mail: mariana.cortez@ unila.edu.br.

Felipe Matias dos Santos é Doutor em Estudos Literários (UFJF). Docente em UNILA. Graduação em Letras - Espanhol e Português como línguas estrangeira. MATIAS, F. S. Literatura e História: aproximações e afastamentos ao longo do tempo. REVISTA ALERE, 15, p. 21-46, 2017. MATIAS, F. S. A representação do sujeito feminino em Carmen, de Prosper Mérimée. Literatura e Autoritarismo (UFSM), 28, p.61-71, 2016. Núcleo de Estudos Portugueses (NEP) - grupo de pesquisa em literaturas lusófonas. E-mail: felipe.matias@unila.edu.br. 